\title{
The good and the bad of vitamin $D$ inactivation
}

\author{
Marie B. Demay \\ Endocrine Unit, Massachusetts General Hospital, Harvard Medical School, Boston, Massachusetts, USA

\begin{abstract}
While disorders of impaired vitamin $\mathrm{D}$ activation and action have long been appreciated, the consequences of abnormalities in pathways leading to the inactivation of vitamin $\mathrm{D}$ metabolites have only recently been identified. Two recent articles have shed new light on this area of vitamin $D$ biology. The report by Martineau et al., published in the $J C l$, describes a pathway in which binding of the vitamin $D$ metabolite $24 \mathrm{R}, 25(\mathrm{OH})_{2} \mathrm{D}_{3}$ to its effector molecule FAM57B2 plays an important role in endochondral ossification during bone repair. This work follows, and adds to, another recent $J \mathrm{Cl}$ publication by Roizen et al., showing that rapid inactivation of vitamin $\mathrm{D}$ metabolites causes vitamin $\mathrm{D}$ deficiency, leading to vitamin $\mathrm{D}$-dependent rickets.
\end{abstract}

in pathways of vitamin D inactivation have only recently been identified (Figure 1B). Homozygous mutations in the vitamin D 24-hydroxylase CYP24A1, the major enzyme responsible for inactivation of 25-hydroxyvitamin D and 1,25dihydroxyvitamin $\mathrm{D}$, lead to idiopathic infantile hypercalcemia (IIH). This disorder is characterized by increased serum concentrations of 25-hydroxyvitamin D and 1,25-dihydroxyvitamin $\mathrm{D}$, hypercalcemia, and hypercalciuria, which leads to nephrocalcinosis. This phenotype emphasizes the nonredundant effects of CYP24A1 in regulating the endocrine actions of active vitamin D metabolites $(8,9)$.

Novel actions of 24R,25dihydroxyvitamin $D_{3}$ While studies in avian models have implicated a role for 24R,25-dihydroxyvita$\min \mathrm{D}_{3}\left[24 \mathrm{R}, 25(\mathrm{OH})_{2} \mathrm{D}_{3}\right]$ in avian fracture repair (10), it is not known whether individuals with IIH have abnormalities in fracture healing. However, a recent study by Martineau et al. identified a nonredundant role for $24 \mathrm{R}, 25(\mathrm{OH})_{2} \mathrm{D}_{3}$ in murine fracture repair (11). In this study, they demonstrate that mice lacking CYP24A1 exhibit impaired fracture healing that is corrected by administration of $24 \mathrm{R}, 25(\mathrm{OH})_{2} \mathrm{D}_{3}$, but not by 1,25 -dihydroxyvitamin $\mathrm{D}$, traditionally thought to be the active metabolite of vitamin $\mathrm{D}$. They identified the transmembrane protein FAM57B2, which interacts specifically with $24 \mathrm{R}, 25(\mathrm{OH})_{2} \mathrm{D}_{3}$. The binding of $24 \mathrm{R}, 25(\mathrm{OH})_{2} \mathrm{D}_{3}$ to FAM57B2 in the fracture callus leads to the production of lactosylceramide, which is necessary for the effects of $24 \mathrm{R}, 25(\mathrm{OH})_{2} \mathrm{D}_{3}$ on callus formation and fracture healing.

It is unclear whether $24 \mathrm{R}, 25(\mathrm{OH})_{2} \mathrm{D}_{3}$ needs to be synthesized at the fracture site, or whether circulating levels are sufficient to exert its beneficial effects. The observation that an absence of $24 \mathrm{R}, 25(\mathrm{OH})_{2} \mathrm{D}_{3}$ impairs the maturation of chondrocytes, which are in an avascular part of the repair callus, sug- 
A

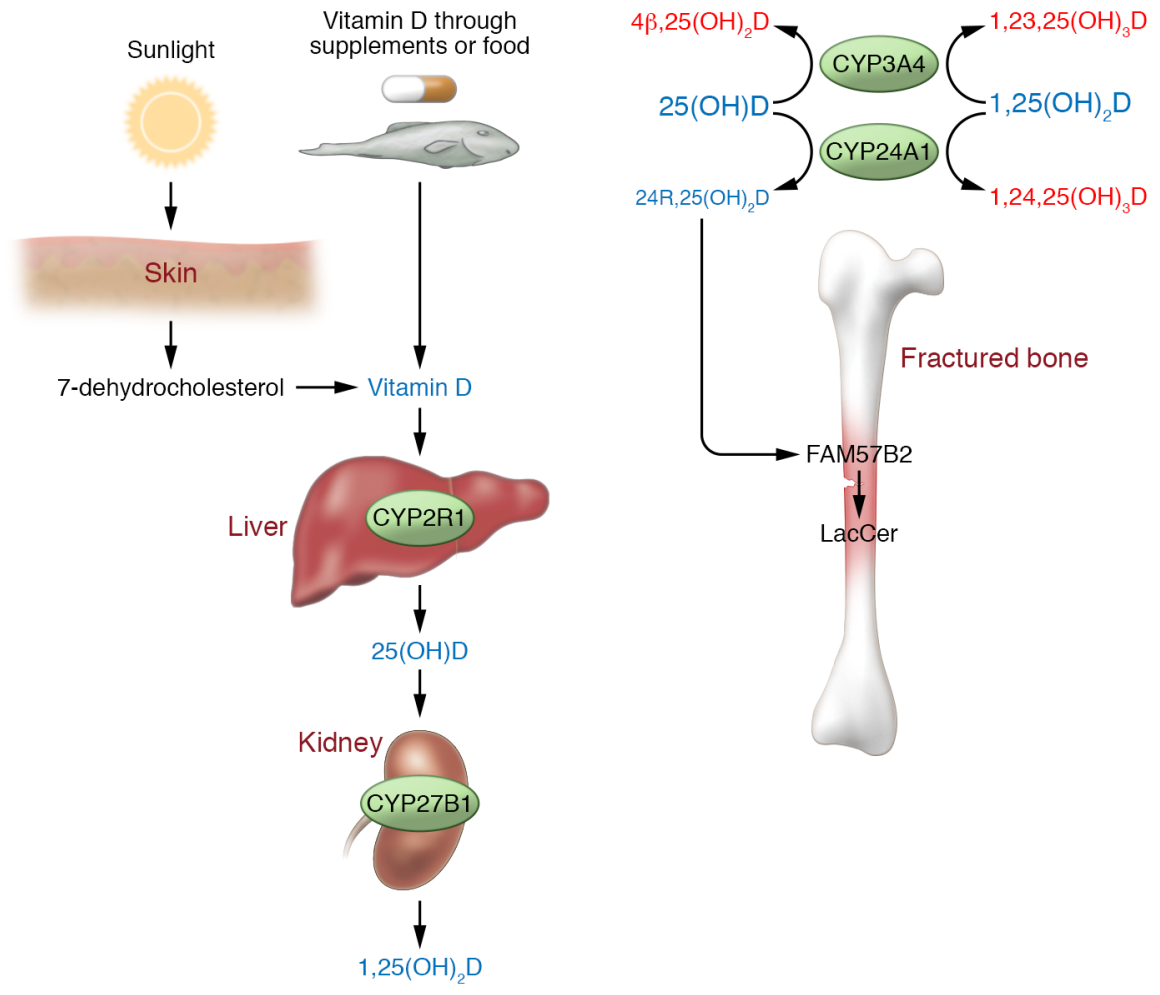

Figure 1. Vitamin D synthesis and metabolism. (A) Ultraviolet radiation results in the conversion of 7-dehydrocholesterol to pre-vitamin $D$, which isomerizes to vitamin $D$ in the skin. Vitamin $D$ can also be obtained from nutrition. Vitamin $D$-binding protein transports vitamin $D$ to the liver, where it undergoes 25 -hydroxylation by CYP2R1. CYP27B1 further hydroxylates 25 -hydroxyvitamin $D$ at the 1- $\alpha$ position, resulting in the formation of the active hormone 1,25-dihydroxyvitamin $\mathrm{D}$. Although this latter enzyme is widely expressed, the kidney is thought to be the major source of circulating 1,25-dihydroxyvitamin D. (B) Vitamin D metabolites are 24-hydroxylated by CYP24A1. While these metabolites were previously thought to be inactive, binding of $24 \mathrm{R}, 25(\mathrm{OH})_{2} \mathrm{D}_{3}$ to FAM57B2 in the fracture callus leads to the production of lactosylceramide (LacCer), which is essential for the effects of $24,25(\mathrm{OH})_{2} \mathrm{D}$ on callus formation and fracture healing. While CYP3A4 plays a minor role in normal vitamin D physiology, a dominant gain-of-function mutation in CYP3A4 leading to accelerated vitamin D inactivation has recently been identified as the molecular basis for two cases of early-onset rickets. Vitamin $D$ metabolites thought to be inactive are shown in red.

gests the importance of local synthesis of $24 \mathrm{R}, 25(\mathrm{OH})_{2} \mathrm{D}_{3}$. Why the absence of $24 \mathrm{R}, 25(\mathrm{OH})_{2} \mathrm{D}_{3}$ does not result in similar impairment of maturation of the endochondral skeleton remains unknown (12). However, potential paracrine signaling between the maturing growth plate, perichondrium, and marrow may lead to a functional redundancy that is absent in the fracture callus.

\section{Mutation in an alternative pathway of vitamin D inactivation leads to rickets}

Activating mutations of CYP24A1 would be expected to lead to rickets as a result of accelerated inactivation of 25-hydroxyvitamin $\mathrm{D}$ and 1,25-dihydroxyvitamin D, but no mutations have been reported.
However, another recent publication in the JCI by Roizen et al. identified a dominant gain-of-function mutation in CYP3A4 leading to accelerated vitamin $D$ inactivation in two cases of early-onset rickets (13). While this enzyme is thought to play a minor role in normal vitamin D physiology, induction of CYP3A4 underlies the accelerated metabolism of vitamin $\mathrm{D}$ observed with several pharmacological agents. The mutation in the substrate recognition site of CYP3A4 seen in affected individuals increases the rate of 1,25-dihydroxyvitamin $\mathrm{D}$ inactivation by 10 -fold versus WT CYP3A4, and by 2 -fold versus CYP24A1, the principal pathway for inactivation of active vitamin D metabolites (13). Interestingly, a dramatic variability in CYP3A4 expression and catalytic activity has been reported in the general population (14). While this variability could be due to genetic polymorphisms, induction of this enzyme by pharmacological agents and other exogenous compounds may also play a role. Notably, induction of the alternative CYP3A4 pathway of vitamin $D$ metabolism by rifampin is being used to treat IIH patients with CYP24A1 mutations (15).

\section{Unanswered questions}

While the effect of mutations that impair activation of the vitamin D prohormone to 1,25-dihydroxyvitamin $\mathrm{D}$ have long been appreciated, recently identified abnormalities in vitamin $\mathrm{D}$ catabolism raise the question as to whether altered activity or polymorphisms of these enzymes contribute to the unexplained variability in vitamin $\mathrm{D}$ intake required to maintain vitamin $\mathrm{D}$ sufficiency in the general population. Whether individuals with IIH, who cannot synthesize $24 \mathrm{R}, 25$ $(\mathrm{OH})_{2} \mathrm{D}_{3}$, have impaired fracture healing is not yet known. However, investigations of FAM57B2 structure and function have the potential to identify novel therapeutic targets for skeletal repair.

Address correspondence to: Marie B. Demay, Endocrine Unit, Thier 11, Massachusetts General Hospital, 50 Blossom St., Boston, Massachusetts 02114, USA. Phone: 617.726.3966; Email: demay@ helix.mgh.harvard.edu.

1. Hess AF, Unger LJ. The cure of infantile rickets by artificial light and by sunlight. Proc Soc Exp Biol Med. 1921;18(8):298.

2. Steenbock H, Black A. The induction of growth-promoting and calcifying properties in a ration by exposure to ultraviolet light. J Biol Chem. 1924;61:405-422.

3. Cheng JB, Levine MA, Bell NH, Mangelsdorf DJ, Russell DW. Genetic evidence that the human CYP2R1 enzyme is a key vitamin D 25-hydroxylase. Proc Natl Acad Sci U S A. 2004;101(20):7711-7715.

4. Thacher TD, Fischer PR, Singh RJ, Roizen J, Levine MA. CYP2R1 mutations impair generation of 25-hydroxyvitamin $\mathrm{D}$ and cause an atypical form of vitamin D deficiency. JClin Endocrinol Metab. 2015;100(7):E1005-E1013.

5. Zhu JG, Ochalek JT, Kaufmann M, Jones G, Deluca HF. CYP2R1 is a major, but not exclusive, contributor to 25-hydroxyvitamin D production in vivo. Proc Natl Acad Sci U S A 2013;110(39):15650-15655.

6. Kitanaka S, et al. Inactivating mutations 
in the 25-hydroxyvitamin D3 1 $\alpha$-hydroxylase gene in patients with pseudovitamin D-deficiency rickets. N Engl J Med. 1998;338(10):653-661.

7. Hughes MR, et al. Point mutations in the human vitamin D receptor gene associated with hypocalcemic rickets. Science. 1988;242(4886):1702-1705.

8. Schlingmann KP, et al. Mutations in CYP24A1 and idiopathic infantile hypercalcemia. $\mathrm{N}$ EnglJ Med. 2011;365(5):410-421.

9. Dauber A, et al. Genetic defect in CYP24A1, the vitamin D 24-hydroxylase gene, in a patient with severe infantile hypercalcemia. JClin Endocrinol Metab. 2012;97(2):E268-E274.
10. Seo EG, Einhorn TA, Norman AW. 24R,25dihydroxyvitamin D3: an essential vitamin D3 metabolite for both normal bone integrity and healing of tibial fracture in chicks. Endocrinology. 1997;138(9):3864-3872.

11. Martineau C, et al. Optimal bone fracture repair requires $24 \mathrm{R}, 25$-dihydroxyvitamin $\mathrm{D}_{3}$ and its effector molecule FAM57B2. JClin Invest. 2018;128(8):3546-3557.

12. St-Arnaud R, et al. Deficient mineralization of intramembranous bone in vitamin D-24hydroxylase-ablated mice is due to elevated 1,25-dihydroxyvitamin $\mathrm{D}$ and not to the absence of 24,25-dihydroxyvitamin D. Endocrinology.
2000;141(7):2658-2666.

13. Roizen JD, et al. CYP3A4 mutation causes vitamin D-dependent rickets type 3.J Jlin Invest. 2018;128(5):1913-1918.

14. Hohmann N, Haefeli WE, Mikus G. CYP3A activity: towards dose adaptation to the individual. Expert Opin Drug Metab Toxicol. 2016;12(5):479-497.

15. Hawkes CP, Li D, Hakonarson H, Meyers KE, Thummel KE, Levine MA. CYP3A4 induction by Rifampin: an alternative pathway for vitamin D inactivation in patients with CYP24A1 mutations. JClin Endocrinol Metab. 2017;102(5):1440-1446. 